\title{
Notes on Writing from Writers of Note
}

\section{COMMUNICATION CORNER No. 37}

\author{
by Philip Yaffe
}

\section{Editor's Introduction}

Each "Communication Corner" essay is self-contained; however, they build on each other. For best results, before reading this essay and doing the exercise, go to the first essay "How an Ugly Duckling Became a Swan," then read each succeeding essay.

A distinction is often made between creative writing (fiction) and expository writing(non-fiction). However, they are more alike than most people think. Creative writers can learn from expository writers, and vice versa. 


\title{
Notes on Writing from Writers of Note
}

\author{
COMMUNICATION CORNER No. 37
}

\section{by Philip Yaffe}

When I am introduced at social gatherings, the host or hostess usually says: "Hi, I want you to meet Philip Yaffe. He is a professional writer." I almost always get the same response: "Oh, really. What type of novels do you write?" In other words, people automatically associate the term "writer" with "literature," as if fiction were the only type of writing. It isn't. And for most ordinary people, such as myself, it is the least important, yet it always seems to take pride of place.

Scholastic snobbery has a lot to do with this.

Virtually every secondary school and many universities require students to take courses in literature. However, virtually no one who takes such courses will ever write a novel, a stage play, a film script, or any other form of fiction. On the other hand, few schools and universities require students to take courses in writing non-fiction. Yet virtually everyone needs these skills to produce reports, memos, letters, marketing plans, company newspapers, and all the other types of non-fiction texts essential for getting on in life.

Internet searches for quotations about writing almost invariable turn of the thoughts of novelists, poets, playwrights, etc., again as if fiction were the only category of writing of any consequence.

I made such a search to put together this essay. At first, I was disappointed by the lopsided results, but on further reflection they turned out to be quite fortuitous.

I normally make a strong distinction between "creative writing" (fiction) and "expository writing" (non-fiction). In fact, this difference is the foundation of a book I wrote on the subject, where I explained how and why they are truly very different genres. Nevertheless, when reviewing the quotations, it became apparent that the feelings and emotions of good writers in both genres are remarkably similar.

Thus, whether we are creative writers (the tiny minority of us) or expository writers (most of us), we can all learn something from these renowned writing practitioners.

For convenience, I have tried to categorize their insightful quotations. However, creative writing and expository writing are both highly unified activities. Their fundamental features are so intimately interwoven that any attempt to separate them must necessarily fail. Nevertheless, 
August 2021

pretending to decouple them helps organize our thoughts. So, with no apologies for any "miscategorized" quotes, here is what these respected writers had to say.

\section{THE ESSENCE OF GOOD WRITING}

Inventor Thomas Edison once said, "Genius is 1 percent inspiration and 99 percent perspiration." In other words, it's hard work. The same is true of writing, both creative and expository. This is good news, because it means that even the least inspired of us can write well if we are just willing to expend the necessary energy.

Here are a few more quotations along the same line.

"A writer is somebody for whom writing is more difficult than it is for other people." - Thomas Mann

"The secret of good writing is to say an old thing in a new way or to say a new thing in an old way." - Richard Harding Davis

"Good writing is clear thinking made visible." - Bill Wheeler

"Writers must constantly ask: what I am trying to say? Surprisingly often, they don't know." William Zinsser

"There are two kinds of writers in the world: bad writers and improving writers." - William Blundell

"Every writer I know has trouble writing." - Joseph Heller

"Good writing is hard work" - Snoopy (Charles Schulz)

\section{WRITING AS DISCOVERY}

"I know very dimly when I start what's going to happen. I just have a very general idea, and then the thing develops as I write." - Aldous Huxley

"There are thousands of thoughts lying within a man that he does not know till he takes up the pen and writes." - William Makepeace Thackeray

"The act of writing is the act of discovering what you believe." - David Hare 
"Writing became such a process of discovery that I couldn't wait to get to work in the morning. I wanted to know what I was going to say." - Sharon O'Brien

"I never know what I think about something until I read what I've written on it." - William Faulkner

In other words, if you believe you have nothing to say, pick a topic and start writing. You may surprise yourself.

\section{OBJECTIVES OF GOOD WRITING}

"We are cups, constantly and quietly being filled. The trick is knowing how to tip ourselves over and let the beautiful stuff out" - Ray Bradbury

"I write because I'm afraid to say some things out loud" - Anonymous.

"The skill of writing is to create a context in which other people can think." - Edwin Schlossberg "When I sit down at my writing desk, time seems to vanish. I think it's a wonderful way to spend one's life" - Erica Jong

\section{TECHNIQUES OF GOOD WRITING}

"The faster I write, the better my output. If I'm going slow, I'm in trouble. It means I'm pushing the words instead of being pulled by them." - Raymond Chandler

"Work extra hard on the beginning of your story, so it snares readers instantly. And know how you're going to end your story before you start writing. Without a sense of direction, you can get lost in the middle." - Joan Lowery Nixon

"Detail makes the difference between boring and terrific writing. It's the difference between a pencil sketch and a lush oil painting. As a writer, words are your paint. Use all the colors." - Rhys Alexander

"What I like in a good author is not what he says, but what he whispers." - Logan Pearsall Smith.

"Cut out all those exclamation marks. An exclamation mark is like laughing at your own jokes." - F. Scott Fitzgerald

"Nothing is so simple that it cannot be misunderstood" - Jr. Teague 


\section{WRITING AND REWRITING}

"I'm not a very good writer, but I'm an excellent rewriter." - James Michener

"Having imagination, it takes you an hour to write a paragraph that, if you were unimaginative, would take you only a minute. Or you might not write the paragraph at all." - Franklin P. Adams

"Write your first draft with your heart. Re-write with your head." - Anonymous

"The time to begin writing an article is when you have finished it to your satisfaction. By that time you begin to clearly and logically perceive what it is you really want to say." - Mark Twain

"I have made this (letter) longer, because I have not had the time to make it shorter" - Blaise Pascal

"I didn't have time to write a short letter, so I wrote a long one instead." - Mark Twain

In other words, the first draft is almost always too long and poorly structured. To be clear and concise requires at least a second draft, and often more. Or put more succinctly: "The first draft of anything is sh*t." -- Ernest Hemingway

\section{CLARITY AND CONCISENESS}

"When something can be read without effort, great effort has gone into its writing." - Enrique Jardiel Poncela

"Easy reading is damn hard writing." - Nathaniel Hawthorne

"What is written without effort is in general read without pleasure." - Samuel Johnson

"Resist the temptation to try to use dazzling style to conceal weakness of substance." - Stanley Schmidt

"The writer does the greatest good who gives his reader the most knowledge and takes from him the least time." - Sydney Smith

\section{STYLE AND WORDS}


"I love writing. I love the swirl and swing of words as they tangle with human emotions." - James Michener

"A good style should show no signs of effort. What is written should seem a happy accident." W. Somerset Maugham

"You write to communicate to the hearts and minds of others what's burning inside you. And we edit to let the fire show through the smoke. - Arthur Polotnik

"Writers must rely more on the feel of a sentence than on the dictates of a rule book." - James J. Kilpatrick

"The difference between the right word and the almost right word is the difference between lightning and a lightning bug." - Mark Twain

\section{EGOISM UNBOUND}

Few writers ever have the opportunity to quote themselves. I don't know if anything I have ever said will be remembered a hundred years from now, or even a hundred minutes from now. But for what they are worth, here are a few ideas I have encountered, developed, and believed in for more than 40 years.

"Convoluted writing is easy, it takes little thought. Simple writing is difficult; it takes all the thinking you can -and then some."

"Simple writing is a challenge whose rewards are boundless. Once a writer recognizes this, everything else falls into place."

"Good writing - and by extension good speaking - depend on only a handful of fundamental principles. Once you have mastered these, all the tips and techniques for applying them become almost self-evident."

"Clarity can be defined as a quasi-mathematical formula, which is also a recipe for effectively applying it. To be clear, you must do three things:

- Emphasize what is of key importance.

- De-emphasize what is of secondary importance.

- Eliminate what is of no importance.

In short: $\mathrm{CL}=\mathrm{EDE}$

"Conciseness can be defined as a quasi-mathematical formula, which is also a recipe for effectively applying it. To be concise, your text must be as: 
3. Long as necessary, i.e., adequately cover all essential material

4. Short as possible, i.e., avoid all superfluous words, sentences and paragraphs In short: $\mathrm{Co}=\mathrm{LS} "$

"Clarity and conciseness are two sides of the same coin. To be clear, you must be concise. Unnecessary verbiage obscures, so it must be eliminated. Likewise, to be concise, you must be clear. Only by knowing precisely what you want to say can you eliminate obscuring words, sentences, and paragraphs."

"Writing is like cooking. You assemble the ingredients and start mixing. When the lifeless liquid begins to stiffen and take shape, you know you are making a cake. For me, the feeling is really that physical."

"Continually ask yourself: 'Why the hell should anyone want to read what I am writing?' If you can't give at least three good reasons, stop writing and start thinking. Otherwise, you will be wasting everyone's time-principally your own."

"Aim for the lowest common denominator. Virtually no one will object that your text is too easy, but some may object that it is too difficult. Focus on the readers who may not understand; they are your true audience. The others will not complain."

"The basic principles of good writing and speaking are few and easy to understand. Unfortunately, most books on the subject bury them under an avalanche of tips and techniques."

"Don't let good grammar get in the way of good writing."

Having written several books, let me conclude with something I wish I had said, but in fact comes from someone else.

"Don't write merely to be understood. Write so that you cannot possibly be misunderstood." Robert Louis Stevenson

You will never find better advice.

\section{About the Author}

Philip Yaffe was born in Boston, Massachusetts, in 1942 and grew up in Los Angeles, where he graduated from the University of California with a degree in mathematics and physics. In his senior year, he was also editor-in-chief of the Daily Bruin, UCLA's daily student newspaper. He has more than 40 years of experience in journalism and international marketing communication. At various points in his career, he has been a teacher of journalism, a reporter/feature writer with The Wall Street Journal, an account executive with a major international press relations 
agency, European marketing communication director with two major international companies, and a founding partner of a specialized marketing communication agency in Brussels, Belgium, where he has lived since 1974. He is the author of more than 30 books, which can be found easily in Amazon Kindle.

DOI: $10.1145 / 3481719$ 